Session 3253

\title{
A Successful Freshman Engineering Course: an Active Learning Experience
}

\author{
Arthur M. Clausing \\ Dept. of Mechanical and Industrial Eng. \\ University of Illinois at Urbana-Champaign
}

\begin{abstract}
This paper describes a highly successful freshman engineering course that has been developed and taught for the last four years in the Department of Mechanical and Industrial Engineering at the University of Illinois at Urbana Champaign. This course is taught with a section size of 20 or fewer students with a faculty member and "Learning Assistant" assigned to each section. Nine sections of this one credit-hour course have been offered each fall semester with a typical total course enrollment of 180 students. This paper addresses why the value of this course greatly transcends that of a typical one-hour course, and how a maximum section size of 20 can be maintained at a large research university without undo demands on our faculty.
\end{abstract}

The stated objectives of this course are: (i) to introduce our students to the fields of mechanical and industrial engineering in a small-section environment; (ii) to develop communication, computer, and team building skills, and (iii) to conduct a detailed examination of a commercial product in order to understand its engineering content. Currently, a two-cycle leaf blower is disassembled, studied, reassembled, and tested.

\section{Course Objectives and Goals}

The course described in this paper has been taught for the last four years in the Department of Mechanical and Industrial Engineering (M\&IE) at the University of Illinois at UrbanaChampaign (UIUC). The objective that precipitated the development of this course was a desire to establish much earlier contact with our entering freshmen. Five years ago, the first departmental course taken by our students was in the first semester of their junior year. As a consequence, many of our potential graduates had transferred to another major or dropped out of the university before they had been exposed to an M\&IE course or faculty member.

For a freshman course to be a quality experience and accomplish many of our objectives, we concluded that a small class size was an absolute necessity. Thus, we have limited the size of the sections of our "Discovery Seminar" to 20 students and have taught nine sections of our course each of the past four fall semesters. Each of these nine sections is taught jointly by a faculty member and an outstanding senior-the Learning Assistant (LA). This arrangement ensures that each incoming freshman learns to know well an M\&IE faculty member, one of our outstanding seniors, and several of their classmates during their very first semester on campus.

The course consists of two one-hour lectures, nine two-hour laboratory periods, and a one-hour tour of selected departmental laboratories, teaching and research, and student projects, for 
example, Formula SAE cars. The course concludes three weeks before the end of the semester; hence, it is completed before these incoming freshmen face the final round of hour examinations and final examinations. The faculty member and LA that are assigned to each section are responsible for the laboratory periods and both attend all nine of these two-hour sessions. Thus, we have a ratio of one instructor for every ten students.

The use of Learning Assistants has many advantages. Specifically:

1. The small student-faculty ratio enables us to use active learning techniques that we have found to be very effective.

2. Freshmen relate well to our upper-class students. Upperclassmen can address issues associated with college and campus life that the faculty is unable to address.

3. A large fraction of the work load (the load associated with offering nine sections of this course) is borne by the Learning Assistants. For example, they are responsible for virtually all of the course mechanics: announcing assignments, meeting times and locations, due dates of assignments and projects, etc. They also examine all of the tutorials and grade all of the exercises. The extra help provided by the Learning Assistants enables us to have students in the class redo assignments and rewrite reports that fall short of our expectations. Collectively, the LAs also staff the tutorial room where the students in the class go to obtain extra help and complete the computer assignments. The outstanding seniors who staff our tutorial room are able to provide help on all technical subjects (math, chemistry, physics, etc.).

The nine sections of our course are usually taught by nine different faculty members. The intention is to rotate our entire faculty through this course. This enables us to assign the students in each section to the faculty member as advisees. Thus, the relationships developed during the many one-on-one interactions in our Discovery Seminar continue to grow during the balance of the student's college education. All students immediately have several persons to turn to for advise on career decisions, summer internships, scholastic or personal problems, etc. The process of getting to know our students is launched with the first assignment which is: send your instructors an e-mail message providing them with an autobiographical sketch.

A key objective for any course is to make it a high quality experience. If one is using a small class size to improve the freshman experience, the load on the faculty becomes critical in medium or large enrollment programs. Hence, another objective is to minimize the faculty load. How are these two objectives - objectives that may appear to be mutually exclusiveaccomplished? We achieve these two objectives by: (i) using outstanding seniors to assist in the instruction, (ii) offering a highly structured course with unstructured class sessions, and (iii) placing the responsibility of designing and orchestrating the course on a single faculty member.

The important role played by our LAs has been discussed. Consider next why one should offer a highly structured course with unstructured class sessions. This might seem like another contradiction. First, we quickly learned that incoming freshmen are expecting to be told what, when, how, and why. There is a day and night difference, for example, between the quality of their oral presentations with and without a 15 minute, a priori lecture on oral presentations. Second, if the course has little structure, each instructor must create his or her own course every semester. This is especially hard to do in a freshman course with no history of implied content and no stable of suitable textbooks. Little can be passed from instructor to instructor. This is 
especially disastrous when a significant portion of the course is to be conducted by a different set of seniors each year.

Having a structured course enabled us to prepare two course manuals — an instructor's manual and a student's manual or course book - that contain every sheet of paper needed to teach the course and take the course, respectively. The instructor's manual contains: the syllabus, the class schedule, tutorial room hours, all course material including the assignments, tutorials, dissection exercises, the solutions to all exercises, supplemental notes on selected topics, a list of suggested student projects, etc. Even a schedule of the instructor training sessions and feedback luncheons is contained in the instructor's manual. (The table of contents of the instructor's manual is provided in the next section of this paper.) The instructors do not need to distribute a single sheet of paper to their students during the entire semester. Even the section specific information - section instructors, their e-mail addresses, office addresses and telephone numbers, etc. - is placed in the manuals that are distributed to the students by the course coordinator.

The individual two-hour laboratory sessions of our course are unstructured active learning experiences. There are nine such periods that alternate between the dissection laboratory and a discussion laboratory. A two-stroke leaf blower is being dissected, analyzed, and tested during the "laboratory" periods. Computer software is learned, the engine test data are reduced, and their first laboratory report is written during the alternate "discussion" periods. There is little time available for lecturing during these sessions, and no formal lectures are required in order for the students to complete their assignments. Of course, our faculty naturally inject short presentations on material relative to their areas of expertise in order to make the dissection exercise a meaningful introduction to the engineering education they are about to receive.

For any course, especially a course in a new area, it is vital that a faculty member takes ownership of the course. This is especially true when there is a potential for a relatively large administrative burden, for example, when nine sections of a one credit-hour course are being offered. Much of the work associated with offering the course is done once by the course coordinator and not nine times each semester. The course coordinator carries over the lessons learned from year-to-year. He also conducts tutorials for the faculty and LAs during which he goes through the exercises that are to be completed by the students in future class sessions. Our outstanding seniors as well as our faculty, including the course coordinator himself, are surprised by what they learn from one another.

The benefit to the LAs far transcends the money they earn and the additional entry they have on their resume. Working closely with a faculty member, their self-confidence and leadership skills improve, as well as their oral skills, and their ability to think on their feet. They also get to know several of the other faculty members during the interactions that occur during the feedback luncheons and instructor training sessions. The LAs are given the responsibility of developing the agenda for the feedback sessions that are held several times a semester. They also conduct these sessions. We have had no difficulty recruiting LAs during the past four years. In fact, many students approach us months before the LA selection process begins. We expect our Learning Assistants to take charge, and the 36 outstanding seniors, who served in this course during the past four years, have all met our expectations. 
Finally, consider three things that I feel a freshman course should not do:

1. take credit-hours away from the core curriculum. We elected to offer a one credit-hour course. It is difficult for graduates to build on a college education that does not provide them with a structure to build on-those engineering science courses in materials, controls, heat transfer, etc. that we teach so well.

2. consist of a hodgepodge of peripheral topics. In an attempt to help our students succeed, several periods were spent on time management during the first offering of our course. This did not work well because our faculty did not enjoy lecturing on this subject, and our students were more interested in learning about engineering. We now only present a 20 minute module on time management during the second of the two lecture periods in our course. Several publishers are providing booklets on a potpourri of topics for freshman courses. Are we paying too much attention to our course titles and our topical lists, and not enough attention to the quality of our offerings? It is important to set a high standard and to convey our high expectations. It is difficult to do this with a shallow treatment of a potpourri of peripheral topics.

3. cover nothing about everything. I have reviewed the outline of a four credit-hour freshman course currently being offered where all topics in the course outline begin with:

"Introduction to...." What will students retain from four credit-hours of introductions? How does one avoid duplication when such courses are offered in parallel with the physics courses that most engineering students take, to say nothing of the courses that lie later in the curriculum?

\section{Course Content}

The content of our Discovery Seminar can be determined to a great extent from the material contained in the Instructor's Manual. The Table of Contents of the Instructor's Manual is given in Table 1. Currently, this manual consist of 104 pages of material. The subset of this material that is contained in the Student's Manual is also indicated in Table 1. The content and assignments contained in Section 2, Engine Dissection, and Section 3, Computer Tutorials and Assignments, make up the credit portion of the course. The computer skills being developed with the tutorials and assignments in Section 3 are those required to reduce and present the engine test data. These skills are also extensively used in preparing the group project report-a report on a subject related to the engineering system being dissected.

\section{Table 1 The Table of Contents of the Instructor's Manual}

$\begin{aligned} \text { Section } 1 & \text { Course Mechanics (11 pages) } \\ 1.1 & \text { Course Information Sheet }{ }^{\dagger} \text {; Class Roster } \\ 1.2 & \text { Syllabus }^{\dagger} \text {; Instructor \& Section Data }{ }^{\dagger} \text {; Tutorial Room Hours }{ }^{\dagger} \\ 1.3 & \text { Course Content and Weekly Tasks } \\ 1.4 & \text { Responsibilities of Instructors } \\ 1.5 & \text { Tour Schedule } \\ 1.6 & \text { Schedule: Instructor Training Sessions and Other Meetings }\end{aligned}$

Section 2 Engine Dissection (35 pages)

2.1 Overviews

(a) Engine Operating Cycles $\dagger$

(b) Slider Crank Mechanism ${ }^{\dagger}$ 
2.2 Dissection Exercises ${ }^{\dagger}$ with Solutions

2.3 Group Project)

- Topics ${ }^{\dagger}$

- Report requirements ${ }^{\dagger}$

- Oral Report Evaluation Sheet

2.4 Engine Test ${ }^{\dagger}$ with Representative Results (See Section 3.3)

Section 3 Computer Tutorials and Assignments (36 pages)

3.1 Microsoft Excel Tutorial and Assignment' with Solutions

(a) Notes on Least-Squares Curve Fitting ${ }^{\dagger}$

(b) Selected Notes on Microsoft Excel ${ }^{\dagger}$

3.2 KaleidaGraph Tutorial and Assignment ${ }^{\dagger}$ with Solutions

(a) Notes on Simple Descriptive Statistics ${ }^{\dagger}$

(b) Selected Notes on KaleidaGraph ${ }^{\dagger}$

3.3 Microsoft Word and Equation Editor Tutorial; Engine Test Report ${ }^{\dagger}$

(See Section 2.4 for Representative Results)

Section 4 Guides and Overviews (21 pages)

4.1 Technical Report Writing Guide ${ }^{\dagger}$

4.2 Oral Presentations ${ }^{\dagger}$

$\uparrow$ Material contained in the student version of the course booklet

We have found the two-stroke leaf blower to be an excellent engineering system for accomplishing the objectives of our dissection exercise. This system enables us to address all of the core subjects contained in the mechanical and industrial engineering curricula. The exercises that each student must complete during the dissection are a key element of this activity. They force the students to try to understand the engineering principles and link core courses (often listed by name and number) to the subsystems of the engine. These exercises transform the dissection from what might be misconstrued to be a trade school drill to an introduction to the core of our engineering discipline. The last group to complete the reassembly of the engine is undoubtedly the one that benefits the most from the dissection.

The students work in a maximum group size of four with an engine assigned to each group. (Forty-five engines are required to support all of our groups.) The engine experiment is also performed with the same four-person group. The students do not test the engine they are dissecting; rather, the same engine is tested by all groups. This practice: (i) enables us to conduct the engine test early in the course while their dissected engines are still in pieces; hence, the data are available for use in other assignments, (ii) eliminates the oil and gas vapors in the dissection laboratory, (iii) greatly reduces the time required to test the engine and increases the probability that meaningful test data will be obtained.

A representative computer exercise, the Microsoft Excel ${ }^{\circledR}$ Tutorial, is given in Table 2. The spreadsheet in Table 2 is to be completed in this tutorial. The students obtain all of the computer files from the Class Server, including the data files that are used in several of the exercises. The tutorials and assignments cover a spreadsheet application (Microsoft Excel ${ }^{\circledR}$ ), a plotting package (KaleidaGraph ${ }^{\circledR}$ ), and the equation editor and table features of a word processor (Microsoft Word $\left.{ }^{\circledR}\right)$. 


\section{Table 2 Microsoft Excel ${ }^{\circledR}$ Tutorial}

The purpose of this tutorial is to introduce you to Microsoft Excel. Please note: (i) A computer file containing the partially completed spreadsheet (see Page 6 of this paper) is provided for your use. The title of this read-only file is: "Excel Tutorial." (ii) Only single-value functions, not numerical values, are to be entered in the cells as required. These functions are to be defined with relative cell references (e.g., A1) and/or absolute cell references (e.g., A\$1: a relative column and an absolute row; and \$A1: an absolute column and a relative row) so other analogous cells can be filled directly with the appropriate formulas. This is accomplished by selecting the fill handle and dragging it through a selection of adjacent cells or by copying and pasting. (iii) You are to complete and submit the Excel Tutorial before starting to work on the Excel Assignment. Please provide your Learning Assistant with printed and electronic copies of the tutorial.

Part 1 This part of the tutorial is an exercise in the use of relative and absolute cell references. You are to evaluate the function: $\mathrm{e}^{-x} \sin (\mathrm{t})$, for the values of $\mathrm{x}$ and $\mathrm{t}$ indicated. You will only need to enter directly one formula in the $\mathrm{x}=0, \mathrm{t}=0$ cell if you carefully assign relative and absolute cell references as required. After filling the remainder of the array of cells with this formula, check several filled cells to insure that the cell references are indeed correct.

Part 2 In this part, you are to calculate the grade points and grade point averages (GPA) of three students, the average of the GPAs of these students, and the standard deviation of these GPAs. Note the following points: (i) You need only create five formulas to complete Part 2. All other cells can be filled with the fill handle or by copying and pasting one of these five formulas. (ii) Take advantage of the auto sum button (toolbar icon: $\sum$ ) when entering summations. (iii) Cell references can be entered in the formulas you are creating by clicking in the respective cell. This procedure results in fewer errors and is usually faster than typing the respective cell references.

Part 3 You are to determine if the variation of the experimentally determined thermal conductivity, k, of gold with temperature, T, (see Part 3 of Excel Spreadsheet) can be accurately represented by a linear least-squares fit, that is, by an equation of the form: $k=a T+b$. See Section 3.1 (a), "Least-Squares Curve Fitting," for expressions for the constants a and b. Enter in the column labeled " $k(\mathrm{LSF})$ " the values of k determined from your least-squares fit.

\section{Table 2 Microsoft Excel ${ }^{\circledR}$ Tutorial (cont.)}

(Spreadsheet to be completed) 
Name:

Part 1

Given the function $\exp (-\mathrm{x})^{*} \sin (\mathrm{t})$; calculate this function for the values of $\mathrm{x}$ and $\mathrm{t}$ indicated.

(That is: for $\mathrm{x}=0.0,0.1, \ldots 0.5$ and $\mathrm{t}=0.0,0.2, \ldots 1.0$ )

\begin{tabular}{|c|c|c|c|c|c|c|}
\hline $\mathrm{x} \backslash \mathrm{t}(\mathrm{rad})$ & 0.0 & 0.2 & 0.4 & 0.6 & 0.8 & 1.0 \\
\hline 0.0 & & & & & & \\
\hline 0.1 & & & & & & \\
\hline 0.2 & & & & & & \\
\hline 0.3 & & & & & & \\
\hline 0.4 & & & & & & \\
\hline 0.5 & & & & & & \\
\hline
\end{tabular}

\begin{tabular}{|c|c|c|c|c|c|c|c|}
\hline \multicolumn{8}{|l|}{ Part 2} \\
\hline \multicolumn{2}{|l|}{ Fall 1997} & \multicolumn{2}{|c|}{ John Smith } & \multicolumn{2}{|c|}{ Joe Smart } & \multicolumn{2}{|c|}{ Mary Williams } \\
\hline & Hours & Grade & Grade Points & Grade & Grade Points & Grade & Grade Points \\
\hline ME 199 & 1 & 4 & & 4 & & 4 & \\
\hline MATH 120 & 3 & 3 & & 4 & & 4 & \\
\hline RHET 105 & 4 & 2 & & 2 & & 4 & \\
\hline CHEM 101 & 4 & 3 & & 3 & & 3 & \\
\hline GE 103 & 3 & 2 & & 3 & & 4 & \\
\hline ENG 100 & 0 & 4 & & 4 & & 4 & \\
\hline \multicolumn{8}{|l|}{ Total } \\
\hline & & \multicolumn{2}{|c|}{ GPA: } & \multicolumn{2}{|c|}{ GPA: } & \multicolumn{2}{|c|}{ GPA: } \\
\hline
\end{tabular}

Average of three G.P.A's

Standard Deviation of three G.P.A's

\section{Part 3}

Determine the least-squares line that best fits these data, i.e., $\mathrm{k}=\mathrm{aT}+1$

\begin{tabular}{|c|c|c|c|c|c|}
\hline \multirow{5}{*}{} & $\mathrm{T}[\mathrm{K}]$ & $\mathrm{k}[\mathrm{W} / \mathrm{m}-\mathrm{K}]$ & $\mathrm{T}^{\wedge} 2$ & $\mathrm{~T}^{*} \mathrm{k}$ & $\mathrm{k}(\mathrm{LSF})$ \\
\hline & 100 & 327 & & & \\
\hline & 200 & 323 & & & \\
\hline & 400 & 311 & & & \\
\hline & 600 & 298 & & & \\
\cline { 2 - 6 } & 800 & 284 & & & \\
\cline { 2 - 6 } & 1000 & 270 & & & \\
\hline & 1200 & 255 & & & \\
\hline sum: & & & & & \\
\hline
\end{tabular}

Compute the slope "a" and the intercept "b"

\begin{tabular}{|c|c|}
\hline$a=$ & \\
\hline$b=$ & \\
\hline
\end{tabular}




\section{Conclusions}

The conclusions drawn from offering 36 sections of our freshman course during the past four years to over 600 entering students follow.

1. A key that leads to a highly effective freshman course is a small class size. Factors that greatly contribute to a high quality experience-active learning techniques, a class composed of one's advisees, four-person group activities-would not be feasible in a typical large class format.

2. The use of outstanding seniors as Learning Assistants has worked extremely well. It is a win/win situation for all: the freshmen, the Learning Assistants, and the faculty.

3. Learning computer applications is an enjoyable experience using an active learning environment and relevant exercises. Competence is developed in a relatively short time using challenging tutorials and exercises. Potential frustration with difficult exercises is eliminated with our 10 to 1 student-instructor ratio in our active learning environment. Our tutorial room is a very effective means of providing out-of-the-classroom assistance.

4. A small two-stroke leaf blower provides an excellent engineering system for dissecting or reverse engineering because: (i) it can be related to all of our core courses, (ii) it contains sufficient content, and (iii) it provides many options for meaningful laboratory tests and project activities.

5. The inefficiency of offering multiple sections of a one credit-hour course would be too great without a course coordinator who assumes ownership of the course. This requires a structured course. Much of the potentially large overhead of the course can be eliminated by preparing comprehensive instructor and student manuals.

\section{ARTHUR M. CLAUSING \\ Professor Clausing has taught in the Department of Mechanical and Industrial Engineering (M\&IE) at the University of Illinois at Urbana-Champaign since receiving his $\mathrm{PhD}$ in 1963 . He is currently Prof. of ME and Associate Head of M\&IE. He has been designing ME curricula for many years and has attended ME Curriculum meetings with Big Ten ME representatives for the past 10 years.}

